\section{SLEEPING SICKNESS AND BIG GAME :}

\section{A PROPOSED EXPERIMENT'.}

By WARRINGTON YORKE, M.D., DIRECTOR OF THE RUNCORN RFSEARCH LABORATONIES OF THE LIVERPOOL SCHOOL OF TROPICAL MEDICINE.

DuRING the years 1908 and 1909 the diagnosis of several cases of human trypanosomiasis amongst Europeans, who had never been in contact with Glossina palpalis, drow attention to the occurrence of the disease in portions of Rhodesia and Nyasaland in which this particular insect does not exist.

In 1910 it was shown that the parasite causing the disease in Rhodesia and Nyasaland differed in certain respects from that causing sleeping sickness in other portions of tropical Africa. The name Trypanosoma rhodesiense was given to this new parasite. Since these discoveries many cases of sleeping sickness have been found in Rhodesia and Nyasaland, and in 1911 Dr. Kinghorn and $I$ were sent to North-Eastern Rhodesia to investigate and report upon the conditions governing the spread of the disease in that country.

The first problem we had to solve was to ascertain the vector responsible for the spread of sleeping sickness in a country where Glossina palpalis does not exist. Now, although Glossina palpalis has not been found either in Nyasaland or in the Luangwa Valley of Rhodesia, yet Glossina morsitans, the tsetse fly which is known to cause "fly" disease in domestic stock, is present in enormous numbers, and it was soon proved by Dr. Kinghorn and myself that it is this fly that is responsible for the spread of human trypanosomiasis. This discovery is one of great practical significance; for whereas the former fly, Glossina palpalis, is limited in its distribution to watercourses, and never found far from the banks of certain rivers or the lake shores, the latter, Glossina morsitans, is ubiquitous, its distribution being quite independent of water. Hence it is obvious that it is impossible to attempt to deal with sleeping sickness in Rhodesia and Nyasaland by any such simple method as removing the native population away from the watercourses and lake shores, a procedure which was attended with such remarkable results in Uganda. The problem of preventing the spread of sleeping sickness in these countries, which a few years ago were thought to be in no danger, is one of infinitely greater difficulty than was that which had to be faced in Uganda.

A large number of wild Glossina morsitans were examined in the Luangwa Valley in order to ascertain what proportion were capable of infecting man with trypanosomiasis. This information is important, as it affords an approximate idea of the potential danger of the district. We found that 1 in 500 wild Glossina morsitans was infective. As this was far too large a proportion to have been infected from the comparatively few infected human beings, it was evident that some other host than man must serve as the reservoir from which the fly derives its infection. With the object of ascertaining what was the chief vertebrate reservoir of the virus, we examined 250 wild animals (including elephant, rhinoceros, hippopotamus, lion, buffalo, fourteen different kinds of antelope, caracal, galago, squirrel, genet, hunting dog, giant rats, and wild rabbits), 256 monkeys, 35 domestic stock, 142 wild rats, and 15 wild mice, making a total of 698. The results were striking; a large proportion of the antelope were found to be infected with the parasites which cause sleeping sickness in man and trypanosomiasis in domestic stock. As a conservative estimate, the percentage of game infected with the trypanosomes of man or domestic stock might at Nawalia in the Luangwa Valley be placed at 50, and at Ngoa on the Congo Zambesi watershed at 35 .

Beyond stating that the figures in the accompanying tables refer only to the trypanosomes causing disease in man and his flocks and herds, it is unnecessary here to go into details as to their exact nomenclature. I might mention, however, that at Nawalia in the Luangwa Valley 16 per cent. and at Ngoa on the Congo Zambesi watershed 3.3 per cent. of the wild animals were infected with the human trypanosome, $T$. rhodesiense.
TABLE I.-Percentage of Various Species of Game Found Infected with Trypanosomes Pathogenic to Man or Domestic Stock at Navalia, Luangwa Valley.

\begin{tabular}{|c|c|c|c|c|c|}
\hline \multicolumn{4}{|c|}{ Animal. } & \multirow{2}{*}{$\frac{\begin{array}{c}\text { Number } \\
\text { Examined. }\end{array}}{9}$} & \multirow{2}{*}{$\begin{array}{c}\begin{array}{c}\text { Percentage } \\
\text { Harbouring } \\
\text { Trypanosomes. }\end{array} \\
66.6\end{array}$} \\
\hline Bushbuck & ... & ... & ... & & \\
\hline Waterbuck & ... & ... & $\cdots$ & 28 & 60.7 \\
\hline Kudu $\quad \ldots$ & $\cdots$ & ... & $\cdots$ & 7 & 57.1 \\
\hline Hartebeest & $\cdots$ & ... & ... & 6 & 16.6 \\
\hline Roan ... & ... & ... & $\cdots$ & 8 & 12.5 \\
\hline Warthog & ... & ... & ... & 9 & 11.1 \\
\hline Puku $\quad \ldots$ & $\ldots$ & ... & ... & 10 & 10.0 \\
\hline Mpala ... & $\cdots$ & ... & ... & 29 & 6.9 \\
\hline
\end{tabular}

TABLE II.-Percentage of Various Species of Game Found Infected with Trypanosomes Pathogenic to Man or Domestic Stock at Ngoa, Congo Zambesi Watershed.

\begin{tabular}{|c|c|c|c|c|c|}
\hline \multicolumn{4}{|c|}{ Animal. } & \multirow{2}{*}{$\frac{\begin{array}{c}\text { Number } \\
\text { Examined. }\end{array}}{2}$} & \multirow{2}{*}{$\begin{array}{c}\begin{array}{c}\text { Percentage } \\
\text { Harbouring } \\
\text { Trypanosomes. }\end{array} \\
50.0\end{array}$} \\
\hline Sitatunga & $\cdots$ & $\cdots$ & $\cdots$ & & \\
\hline Waterbuck & $\ldots$ & ... & $\ldots$ & 27 & 44.4 \\
\hline Eland ... & $\ldots$ & $\ldots$ & $\ldots$ & 15 & 26.6 \\
\hline Duilier ... & $\ldots$ & $\cdots$ & $\cdots$ & 9 & 22.2 \\
\hline Roan $\quad .$. & $\ldots$ & $\cdots$ & $\ldots$ & 5 & 20.0 \\
\hline Puku ... & $\ldots$ & $\ldots$ & $\ldots$ & 8 & 12.5 \\
\hline
\end{tabular}

This in restigation, therefore, made it clear that the main reservoir of the trypanosomes of man and domestic stock is the big game.

Having ascertained these two essential facts-namely, that the tsetse fly, Glossina morsitans, is the agent by which the disease is spread and that the big game is the inexhaustible reservoir of the virus which causes the disease-we are faced with the problem of what, in the light of this knowledge, call be done to stamp out sleeping sickness or to limit its spread in Nyasaland and Rhodesia. Obviously the most satisfactory means of prevention would be the extermination of Glossina morsitans, which conveys the parasite from one vertebrate host to another. Unfortunately, howerer, this is out of the question at the present state of our knowledge. The only known method of getting rid of the fly from a district is by clearing away the bush. In the immediate vicinity of villages such a procedure is doubtless feasible, and would be attended by valuable results, and natives should be encouraged to do everything possible in this direction. The labour involved in clearing large tracts of country wonld, however, be so great that this method can be at once set aside as impracticable. Moreover, it must be remembered that not only would the country have to be cleared, but it would require to be kept cleared. Every one who has had experience of tropical Africa is familiar with the dense shrub growth which springs up in the site of old garden clearings two or three years after the natives have ceased cultivating the land. This shrub growth is exceedingly favourable to Glossina morsitans, so that, unless the country be kept constantly cleared, the last state of the district, is worse than the first.

At present little is known of the bionomics of Glossina morsitans. Investigations so far carried out indicate that this tsetse fly lias no breeding-places which are peculiar to it, but that its pupae are deposited in a more or less haphazard manner in hollow trees and excavations where they are not likely to be disturbed by game birds. Re. garding the liability of the fly to disease and of its natural enemies practically nothing is known. Much more in. formation is required on this subject, but it seems only too obvious that the investigations will be beset by great difficulties, and that knowledge will only be forthcoming as the result of much slow and tedious work. In fact, to those familiar with morsitans country the extermination of the fly must seem an almost impossible procedure.

In Uganda, where the disease is spread by Glossina 
palpalis, the removal of the population a short distance away from the lake shores and watercourses was followed by most excellent results. Such a measure, however, is impossible in Nyasaland and Rhodesia, where the vector, Glossina morsitans, is practically ubiquitous in its distribution and not limited to watercourses as is Glossina palpalis.

In view of the impossibility of exterminating the fly and of the equal impossibility of removing the population from the fly belts, we must consider the only way that remains of combating the disease - that is, the advisability of attempting to destroy the reservoir of the virus. It is obvious that the mere isolation of infected human beings is futile in view of the fact that the main reservoir, of the virus is the blood of the big game.

Since the beginning of last year, when Dr. Kinghorn and I published our paper announcing the fact that a large proportion of the wild fauna of Africa harboured the trypanosomes of man and domestic stock, a considerable polemic has arisen over the question of the advisability of attempting to exterminate the big game in the vicinity of human habitations in fly areas.

In discussing this subject it appears to me that I could not do better than state briefly what I suggest should be done and then reply to some of the more important criticisms which have been directed against these proposals.

In the first place, I consider that a decisive scientific experiment, the nature of which I will outline later, should be undertaken with a view to ascertaining the effects of completely, eradicating the game in a limited area. As some years must elapse before the results of such an experiment would be known, I suggest that in the meantime the restrictions relating to the killing of game by Europeans and natives should be removed in those portions of the fly areas which are in the vicinity of human habitations.

It has been suggested that if the game be destroyed in any district, the fly, being deprived of its natural source of food, might turn its attention solely to man and his flocks and herds. It appears to me that little importance should be attached to this hypothesis; cattle do not, as a rule, live in the presence of Glossina morsitans, and the fly does not invade villages around which there is a clearing, even though at the present time they could by so doing obtain food, perhaps, still more readily than they do in the bush. Moreover, if the game be removed the reservoir of the infection is destroyed, and therefore in a short time the fly would tend to become non-infective. The bite of non-infective Glossina morsitans hurts nobody. Finally, there is absolutely no evidence indicating that if the big game in any particular district were slaughtered the tsetse fly, unable to obtain blood from these animals, would attack man and domestic stock to a greater extent than at present. It might equally well be urged that if the food supply of the fly be removed the fly would disappear. There is, moreover, a considerable amount of evidence that the tsetse fly spreads with the game. For example, since the rinderpest swept through Central and South Africa sixteen or seventeen years ago the big game has increased enormously in numbers, and with this increase in game there has been a corresponding increase of tsetse fly. Although Glossina morsitans was present in enormous numbers at Nawalia, in the Luangwa Valley, when we were working there, and natives sent out to collect the flies had no difficulty in capturing large quantities within a short distance of the laboratory, the magistrate who was stationed there in 1905 told me that he only occasionally saw tsetse flies at that time.

Again, it has been suggested that the big game might be only one of the reservoirs of the disease, and that the infection might equally well be harboured by the small vermin.

It must be remembered, however, that the small vermin is to a considerable extent nocturnal in its habits; and although Glossina morsitans does occasionally bite at night, especially when the moon is full, yet nobody who has lived in "fly" areas can have any doubt that this is exceptional, and that for practical purposes the fly feeds in the daytime only. Dr. Kinghorn and I examined a large number of small vermin-rats, mice, wild rabbits, etc.- without finding a single instance of natural infec- tion with a pathogenic trypanosome. Furthermore, it must be remarked that there is no evidenoe to show that the small vermin are tolerant of the human trypanosome, as are the big game. In those which we infected experimentally the disease ran an acute course and the animals died. If this be the case with the majority of the small vermin they cannot have the same significance as reservoirs of the virus as have the big game, which can probably harbour the parasite for long periods without exhibiting signs of disease.

The theory has been advanced that cattie and other domestic stock might harbour the human parasite for considerable periods without detriment to health. This, however, is not the case. We found that the trypanosome rapidly kills horses, cattle, donkeys, goats, and dogs. Moreover, even if the human parasite failed to kill domestic stock, these would still die from the ordinary cattle trypanosomes, such as $T$. pecorum, T. nanum, and $T$. vivax, with which the wild Glossina morsitans is heavily infected; so that it is obvious that domestic stock cannot have the same significance as a reservoir of the infection as the antelope, which are tolerant of the trypanosomes pathogenic to man and domestic stock.

The hypothesis that human beings can harbour the parasites for long periods without detriment to health, and thus act as reservoirs of the virus in the same way as the game, is one which I cannot support. Amongst the cases discovered by us several-presumably recently infected-presented practically no symptoms, the only indication of the disease being the presence of trypano somes in the blood, yet without exception they were all dead within six months.

We return, therefore, to the original position. The game is the natural reservoir of the infection; the part of the tsetse fly, Glossina morsitans, is to transfer the virus from the big game to man and his flocks and herds. At the present state of our knowledge we are unable to attack successfully the tsetse fly, nor, unfortunately, is there any prospect of our being able to do so in the near future.

Whether anything would be gained in this direction by slaughtering the big game is still a moot pcint, therefore I will not consider this side of the question, but adrocate the advisability of attempting to drive back the game from inhabited regions solely because the game are the reservoir of the infection.

I might point out here that whether or not other flies, besides Glossina morsitans, be proved eventually to trans. mit the human trypanosome, does not affect the question, further than that, if this be shown to be the case, it simply emphasizes the difficulty of successfully attacking the transmitting agents and demonstrates clearly that if any. thing is to be done it must be in the direction of destroying the reservoir from which Glossina morsitans and the other (hypothetical) vectors derive their infection.

It has been asserted that the proposal to slaughter all game animals in an infected district is unsound in prin ciple, because the game when harried would betake itself to places difficult of access to man or scatter in small herds or in pairs or singly over wide areas, and that should this occur it is highly probable that it might be followed by tsetse, thus spreading the danger of infection to wide areas now free from game and fly.

To such criticism as this it is not difficult to reply. If the game when harassed betook itself to places difficult of access to man, surely this is exactly what is desired. In such places it would no longer be a menace to civilization.

Regarding the second alternative, that the hunted game might scatter into small herds or in pairs and be followed by the tsetse fly, thus spreading the infection over large districts, the obvious rejoinder is that should this occur the game must be destroyed in the new areas, provided these happen to be inhabited regions. Such a contingency is, however, very unlikely, as it is very questionable if small herds of hunted game scattering over wide areas would cause the tsetse fly to migrate with them.

The Colonial Secretary has said that "To talk of the extermination of the wild fauna of a subcontinent is to talk wild nonsense." This is perfectly true, but it is no reason why the game in a definite limited area should not be destroyed. It was further stated that an attempt mado in Nyasaland to get the game in a certain area killed off was, after twelve months, unsuccessful, though the natives 
were encouraged to shoot. This, again, is no argument against the policy suggested, but merely a confession that the experiment was not efficiently performed.

Such experiments as these are unsatisfactory and do not yield any definite results. For reliable information to be obtained it is necessary that the work should be done in a scientific manner, and on a sufficiently large scale in some particular district. A locality which is fairly well populated, and which contains plenty of tsetse fly and game should be chosen. An exact census of the population should be made, and the proportion suffering from trypanosomiasis determined. The same must be done in the case of the domestic animals, if such exist. An index of the percentage of infective tsetse fly must be ascertained. This is most important, as it gives a definite idea of the potential danger of the district. Finally, the game must be completely eradicated, and at the same time the percentage infected with the human and cattle trypanosomes determined, and when once the game has been driven out it must be kept back by vigorous action and not allowed to return. After an interval of some years the population, domestic stock, and tsetse fly must again be carefully examined. Then we should be in a position to decide definitely whether or not driving the wild fauna back from the sites of human habitations in fly areas would be advantageous on a general scale in tropical Africa. As such an experiment as this would take some years to accomplish, I consider that for the present the game laws should be removed in fly areas, and that Europeans and natives should be allowed to kill what they like, especially in the inhabited portions of these areas.

Recently sleeping sickness was discovered in a certain isolated fly belt-the Sebungwe district of Southern Rhodesia-which is roughly about 2,500 square miles in size. On a hurried survey some twelve cases of the disease were found, including one European. The human trypanosome was also found in certain of the antelope in the area. It has been said that the proper way to deal with the situation is to remove the entire population from the fly belt. This at first sight appears an admirable plan, and will certainly save the inhabitants. Is there, however, not another side to the question? When the population is withdrawn there will be established all the couditions of a game reserve. The wild animals will increase and gradually spread and probably with them the fly, until the invasion of surrounding districts demands further removals. Surely it is preferable to make a reasonable attempt to stamp out the disease than at the first alarm to abandon such regions to the game and fly without even attempting to dispute the ground with them.

It is for such reasons as these that I venture to suggest the desirability of undertaking the decisive experiment which I have outlined, as it is only by this means that the exact knowledge necessary for our future guidance can be acquired.

BibliograpHY.

Stephens and Fantham : On the Peculiar Morphology of a Trypanosome from a Case of Sleeping Sickness and the Possibility of its being a New Species (T. rhodesiense). Roy. Soc. Proc., 1910, vol. 1xxxiii. Yorke: On the Pathogenicity of a Trypanosome (T. rhodesiense) from a Case of Sleeping Sickness in Rhodesia. Annals of Trop. Med. and Parasitology, 1910, vol. iv.

Stannus and Yorke: The Pathogenic Agent in a Case of Human Trypanosomiasis in Nyasaland. Roy. Soc. Proc., 1911, vol. 1xxxiv. Kinghorn and Yorke: Reports of the Luangwa Sleeping Sickness Commission. Annals of Trop. Med. and Parasitology, 1912-13, vols. vi and vii.

Medical Notes in Parliament, British Medical Journal, 1912 July 6 th.

Discussion on Sleeping Sickness and Big Game. Proc. Zool. Soc. June, 1913.

A BILL, making insurance against disease and invalidity compulsory in Belgium, was presented to the Chamber some time ago by the Government. The organization of the service will be conflded to the mutual aid societies, to recognized federations, and to mutualist local committees. The State and the employers will contribute, but in a less proportion than those directly interested. The insured will have a right to medical treatment and to a supply of such medicines as may be required; they will also receive one franc a day, starting from the tenth day of illness onvards. Permanent invalids will be pensioned. The maternity beneflt will be thirty francs. The annual tax for non-members of mutual aid societies will be eighteen francs, of which twelve will be allocated for disease, and six for invalidity.

\section{PRELIMINARY REPORT ON AN OUTBREAK OF FEBRILE DISEASE IN AN INDUSTRIAL SCHOOL.}

By K. M. DUNCAN, M.B.GlasG., F.R.C.S.ENG., MEDICAL OFFICER, ST. THOMAS'S INDUSTRIAL SCHOOL; HONORARY ASSISTANT SURGEON, PRESTON ROYAL INFIRMary.

THE cases which form the subject of this communication occurred during the years 1910 and 1911 in St. Thomas's Industrial School, Preston. I have not been able, so far, to complete the investigation to my satisfaction, and hence have delayed recording the cases. At the time when the epidemic terminated I had the strong suspicion that there was a "carrier" in the school. There has not been a chance of clearing up this point since 1911, but on reading the full and careful report by Drs. McGowan and McNeil on a somewhat similar epidemic which occurred in Tranent Industrial School, and was referred to in a note in the British Medical Journal of May 31st, p. 1178, I thought I might place my experience of an unusual series of cases before the profession.

\section{Clinical Description.}

The clinical description of the epidemic in the Preston school tallies exactly with that in the Tranent and other schools, noted in the report mentioned. To put it as briefly as possible, we had to deal with an illness of sudden onset, marked by headache, epigastric pain, vomiting in mild cases of undigested food, but in severe cases of large quantities of a distinctly greenish or yellowish fluid, accompanied in some cases by intense prostration, a temperature varying from normal to $105^{\circ}$, by herpes labialis in a certain proportion, and in 5 cases by definite consolidation at the base of the lungs. In the very worst cases there was a true septicaemic condition. Three of the boys were found dead in bed, having retired apparently well the previous evening; four others died within twentyfour hours of the onset of headache or vomiting. It will be noticed that only five of my cases developed any definite pneumonic condition, although over 80 boys attacked were carefully examined by me.

\section{Post-mortem Findings.}

At the first post-mortem examination made the thyroid and thymus were greatly enlarged, the spleen was slightly enlarged but otherwise normal, and Peyer's patches and mesenteric glands were very pronounced. The lungs were congested but crepitant. Dr. Delépine examined the stomach contents for traces of poison, with a negative result. In the second post-mortem examination a similar enlargement of the lymphoid structures was found, with marked congestion at the bases of both lungs, but no actual hepatization. At the third and fourth post-mortem examinations similar appearances were found. In neither case could I definitely make up my mind that the lungs showed anything beyond hypostatic congestion, nor were the thyroid and thymus so much enlarged as in the first two cases.

I was able to satisfy the coroner's jury in each case by declaring that I considered the deaths due to a pneumococcal or influenzal poison epidemic in the school, and acting virulently on boys suffering from status lymphaticus. I did not feel satisfied, though I thought I was on pretty good ground, as I knew that three of my teachers-the late Sir William Gairdner, the late Dr. Finlayson, and the late Professor Gemmell-had reported on what seemed to be an exactly similar series of cases occurring in a school in Glasgow in 1888, when the diagnoses severally made were malignant influenza, abortive pneumonia, and pneumonia complicating some unknown intoxication.

At the next post-mortem examination the findings were so like what $I$ have seen in an early case of enteric fever that I thought it probable tinere might be some intestinal poison at work. The Peyer's patches and solitary follicles were distinctly congested and enlarged, and the corresponding mesenteric glands varied from the size of a bean to the size of a walnut and were much congested. The spleen was enlarged and soft. The thymus was only slightly enlarged. The thyroid was enlarged and dotted with pin-point abscesses. Loops of bile, punctures from the spleen, scrapings from the mesenteric glands and 